\title{
Upaya Peningkatan Pelayanan Pengolahan Makanan di Instalasi Gizi RSUD X Kota Solok
}

\author{
Nurmaines Adhyka ${ }^{1, *}$, Rizanda Machmud ${ }^{2}$ \\ ${ }^{1}$ Fakultas Kesehatan Masyarakat, Universitas Baiturrahmah, Sumatera Barat, 25586, Indonesia \\ ${ }^{2}$ Fakultas Kedokteran, Universitas Andalas, Limau Manis, Padang, Sumatera Barat, 25127, Indonesia \\ ${ }^{1}$ Email: nurmaines.adhyka@ staff.unbrah.ac.id*; ${ }^{2}$ Email: rizandamachmud@med.unand.ac.id; \\ * corresponding author
}

ARTICLE INFO

Keywords

Nutrition Installation

Hospital

PGRS2013

\section{ABSTRACT}

One of the hospital functions is to providing medical treatment and health recovery service according to regulation. Nutritional installation has one of important facilities that director of hospital had to pay attention. This process starts form planning, producing and distributing food for patient. The important role from this section is providing food to reach suitability diet for patient, it intended to cure the patient and prevent a complication, decrease morbidity and mortality patient. This study purpose to determine the root cause problem in nutritional installation in RSUD X and the alternative solution problems guided by guidelines and regulations of the minister of health. The research method was a field research which data collected by observation, interview and literature review. The result found there had been four factor based on fish bone analysis and the most effective one is makes Nutrition Installation Service Guide.

\section{Pendahuluan}

Rumah sakit merupakan salah satu pelayanan kesehatan yang memiliki fungsi penyelenggaraan pelayanan pengobatan dan pemulihan kesehatan sesuai dengan standar pelayanannya. Sehingga pelayanan pelayanan di rumah sakit harus sesuai dengan persyaratan fasilitas pelayanan yang diatur oleh peraturan menteri kesehatan [1].

Instalasi gizi merupakan salah satu fasilitas pelayanan yang penting di rumah sakit, yang dimulai dari perencanaan, penyediaan, penyelenggaraan hingga distribusi makanan kepada pasien. Pemberian makanan dimaksudkan untuk mencapai kesesuaian diet pasien sehingga tercapainya kesembuhan pasien, mencegah terjadinya komplikasi, menurunkan morbiditas dan mortalitas pasien [2].

Pedoman Pelayanan Gizi Rumah Sakit (PGRS) [3] yang dikeluarkan oleh Kementerian Kesehatan telah mengatur segala macam proses penyelenggaraan makanan. Pengaturan kegiatan pelayanan gizi berdasarkan PGRS dimulai dari kegiatan pelayanan asuhan gizi rawat jalan, asuhan gizi rawat inap, penyelenggaraan makanan sampai dengan penelitian dan pengembangan. Masalahnya minimnya sosialisasi akan kegiatan ini menyebabkan masih ditemukan beberapa rumah sakit yang belum menerapkannya. RSUD X adalah salah satu contoh rumah sakit yang belum menerapkan pedoman pelayanan gizi sesuai dengan standar PGRS, belum ada Standar Operasional Prosedur (SOP) serta alur yang masih tumpang tindih dengan layanan laundry. Selain itu masih ditemukannya ketidaksesuaian diet dengan kebutuhan pasien sehingga pasien kesulitan dalam menghabiskan makanan serta evaluasi akan kepuasan pasien akan makanan yang diberikan tidak pernah dilakukan. Hal ini dikarenakan tenaga juru masak dan ahli gizi yang kurang, masih rendahnya pengetahuan petugas instalasi gizi akan tatacara pengolahan makanan yang baik, minimnya diklat untuk peningkatan pengetahuan serta peralatan yang kurang layak pakai. 
Tujuan penelitian ini adalah untuk menentukan penyebab permasalahan di Instalasi Gizi RSUD X dan alternatif pemecahan masalah berdasarkan pedoman dan peraturan menteri kesehatan.

\section{Metode Penelitian}

Penelitian ini merupakan Penelitian Lapangan (Field Research), dengan metode pengumpulan data observasi, wawancara dan studi pustaka.

2.1 Observasi

Observasi pada penelitian ini, dilakukan di Instalasi Gizi RSUD X dengan tujuan pengamatan dan pencatatan peristiwa pada objek penelitian [4].

\subsection{Wawancara}

Metode pengumpulan data melalui tatap muka dan tanya jawab langsung antara pewawancara (pengumpul data) dengan responden (sumber data) [5]. Responden pada penelitian ini adalah Kepala Instalasi Gizi RSUD X.

\subsection{Studi Pustaka}

Metode ini digunakan untuk membandingkan antara temuan di lapangan dengan pedoman atau panduan yang dikeluarkan oleh pemerintah [6]. Pedoman yang menjadi acuan dalam penelitian ini adalah PGRS Tahun 2013.

\section{Hasil dan Diskusi}

\section{Identifikasi Masalah}

Pelayanan gizi adalah suatu upaya memperbaiki, meningkatkan gizi makanan, dietik masyarakat, kelompok atau individu yang meliputi pengumpulan, pengolahan, analisis, simpulan, anjuran, implementasi dan evaluasi gizi, makanan dan dietik untuk mencapai status kesehatan yang optimal. Untuk mencapai tujuan tersebut maka pelayanan gizi di rumah sakit diberikan dan disesuaikan dengan keadaan pasien berdasarkan keadaan klinisis, status gizi dan metabolisme tubuh. Pelayanan gizi di rumah sakit meliputi kegiatan pelayanan asuhan gizi rawat jalan, asuhan gizi rawat inap, penyelenggaraan makanan sampai dengan penelitian dan pengembangan.

Tabel 1. Hasil Observasi dan Wawancara serta Studi Pustaka di Instalasi Gizi

\begin{tabular}{|c|c|c|}
\hline No & Hasil Pengamatan & Standar PGRS \\
\hline A & & Pelayanan Gizi Rawat Jalan \\
\hline 1 & $\begin{array}{l}\text { Tidak adanya alur Konseling } \\
\text { Gizi }\end{array}$ & $\begin{array}{l}\text { Adanya alur konseling gizi yang dilengkapi dengan pencatatan } \\
\text { data awal pasien, assesmen gizi, diagnosis gizi, intervensi gizi, } \\
\text { anjuran kunjungan ulang dan pencatatn konseling dengan format } \\
\text { ADIME (Assesmen, Diagnosis, Monitoring dan Evaluasi) }\end{array}$ \\
\hline $\mathbf{B}$ & & Pelayanan Gizi Rawat Inap \\
\hline 2 & $\begin{array}{l}\text { Tidak adanya alur koordinasi } \\
\text { pelayanan asuhan gizi }\end{array}$ & $\begin{array}{l}\text { Koordinasi pelayanan gizi dilakukan oleh Dokter Penanggung } \\
\text { Jawab Pelayanan, Perawat Dietisien, Farmasi dan Tenaga } \\
\text { Kesehatan lainnya }\end{array}$ \\
\hline $\mathbf{C}$ & & Penyelenggaraan Makanan \\
\hline 3 & $\begin{array}{l}\text { Tidak adanya Peraturan } \\
\text { Pemberian Makanan Rumah } \\
\text { Sakit (PMRS) }\end{array}$ & $\begin{array}{l}\text { Peraturan Pemberian Makanan Rumah Sakit (PMRS) ditetapkan } \\
\text { oleh pimpinan rumah sakit sebagai acuan dalam pemberian } \\
\text { pelayanan makanan pada pasien dan karyawan yang mencakup } \\
\text { ketentuan macam konsumen yang dilayani, kandungan gizi, pola } \\
\text { menu dan frekuensi makan sehari, dan jenis menu. }\end{array}$ \\
\hline 4 & $\begin{array}{l}\text { Tidak adanya prosedur } \\
\text { Pengolahan Bahan Makanan }\end{array}$ & Adanya prosedur penyelenggaraan makanan \\
\hline $\mathbf{D}$ & & Ketenagaan PGRS \\
\hline 5 & $\begin{array}{lr}\text { Tidak adanya } & \text { pelatihan dan } \\
\text { pendidikan } & \text { tentang } \\
\text { manajemen } & \text { pengelolaan } \\
\text { makanan } & \end{array}$ & $\begin{array}{l}\text { Pembinaan tenaga diperlukan untuk pemberi, memperoleh, } \\
\text { meningkatkan serta mengembangkan kompetensi kerja, } \\
\text { produktivitas, disiplin, sikap dan etos kerja pada tingkat } \\
\text { keterampilan dan keahlian tetertentu, sesuai dengan jenjang dan } \\
\text { kualifikasi jabatan atau pekerjaan. }\end{array}$ \\
\hline
\end{tabular}




\begin{tabular}{|c|c|c|}
\hline $\mathbf{E}$ & & Sarana dan Prasarana PGRS \\
\hline 6 & $\begin{array}{lll}\begin{array}{l}\text { Minimnya } \\
\text { prasarana }\end{array} & \text { sarana } & \text { dan } \\
\end{array}$ & $\begin{array}{l}\text { Adanya daftar sarana dan prasarana yang diperlukan untuk } \\
\text { pengelolaan Instalasi Gizi rumah sakit }{ }^{7}\end{array}$ \\
\hline 7 & $\begin{array}{l}\text { Alur pengelolaan makanan } \\
\text { yang tidak searah }\end{array}$ & $\begin{array}{l}\text { Alur penyelenggaraan makanan harus lah searah untuk keefektifan } \\
\text { kerja }\end{array}$ \\
\hline $\mathbf{F}$ & \multicolumn{2}{|c|}{ Higiene Sanitasi dan Keselamatan Kerja } \\
\hline 8 & $\begin{array}{l}\text { Tidak adanya pemeriksaan } \\
\text { makanan sampel }\end{array}$ & 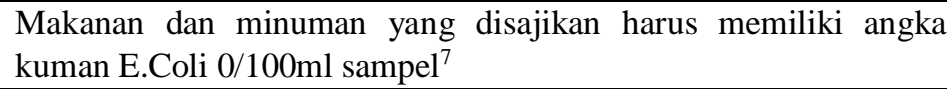 \\
\hline 9 & $\begin{array}{l}\text { Kurangnya sarana prasarana } \\
\text { untuk hygiene sanitasi }\end{array}$ & $\begin{array}{l}\text { Adanya desinfektan untuk peralatan setelah pencucian, adanya } \\
\text { sabun cuci tangan sebelum dan sesudah pengolahan makanan }\end{array}$ \\
\hline 10 & $\begin{array}{l}\text { Tidak adanya pelatihan } \\
\text { kesehatan keselamatan dan } \\
\text { penggunaan APAR. Masih } \\
\text { adanya petugas yang tidak } \\
\text { menggunakan APD }\end{array}$ & $\begin{array}{l}\text { Adanya pelatihan kesehatan dan keselamatan kerja. Adanya kotak } \\
\text { P3K dan pelatihan penggunaan APAR serta kepatuhan petugas } \\
\text { menggunakan APD selama dalam proses pengolahan }\end{array}$ \\
\hline G & \multicolumn{2}{|r|}{ Penelitian dan pengembangan } \\
\hline 11 & $\begin{array}{l}\text { Tidak dilakukannya } \\
\text { penelitian dan } \\
\text { pengembangan }\end{array}$ & $\begin{array}{l}\text { Penelitian dan pengembangan diperlukan untuk mencapai kualitas } \\
\text { pelayanan gizi yang berdaya guna }\end{array}$ \\
\hline
\end{tabular}

Berdasarkan hasil identifikasi masalah, wawancara dan studi pustaka diatas diatas, maka dapat diketahui beberapa hal yang harus diperbaiki dalam pelayanan instalasi gizi RSUD Arosuka.

1. Tidak adanya alur Konseling Gizi

Pasien yang menginginkan pelayanan konsultasi gizi harus mendapatkan surat rujukan dari dokter spesialis. Dietisien melakukan asesmen gizi dimulai dengan pengukuran antropometri pada pasien berupa data $\mathrm{TB}, \mathrm{BB}$, riwayat personal, hasil pemeriksaan lab dan fisik klinis (bila ada) [8]. Dietisien memberikan intervensi gizi berupa edukasi dan konseling dengan langkah menyiapkan dan mengisi leaflet flyer/brosur diet, jadwal, jenis, jumlah bahan makanan sehari menggunakan alat peraga food model, menjelaskan tentang makanan yang dianjurkan dan tidak dianjurkan, cara pemasakan dan lain-lain yang disesuaikan dengan pola makan dan keinginan serta kemampuan pasien.

2. Tidak adanya alur koordinasi pelayanan asuhan gizi

Pemberian pelayanan berupa asuhan gizi pada pasien rawat inap memerlukan koordinasi yang baik antara dokter, perawat, dietisien. Adapun alur dalam koordinasi pelayanan asuhan gizi adalah sebagai berikut :
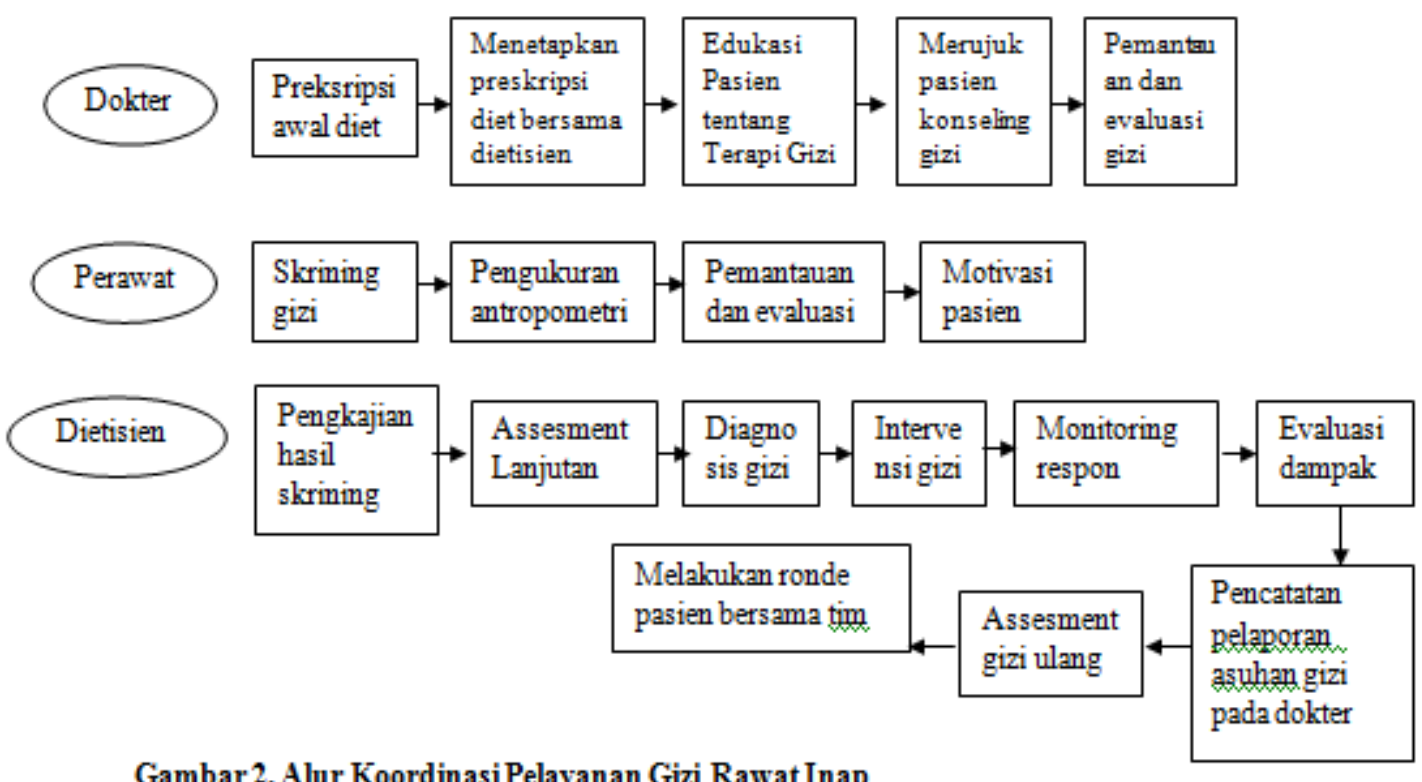

Gambar2, Alur Koordinasi Pelayanan Gizi Rawat Inap

Sumber:-Pedoman Pelayanan Gizi Rumah Sakit, 2013 
3. Tidak adanya Peraturan Pemberian Makanan Rumah Sakit (PMRS)

Penyelenggaraan makanan di RSUD Arosuka menggunakan sistem swakelola dimana instalasi gizi/unit gizi bertanggung jawab terhadap pelaksanaan seluruh kegiatan penyelenggaraan makanan. Berdasarkan PGRS pelaksanaan gizi di rumah sakit harus memilihi Buku Panduan Pelayanan, serta petunjuk teknis setiap kegiatan. Buku Panduan Pelayanan Gizi Rumah Sakit pemberian makanan ini harus mencakup ketentuan macam konsumen yang dilayani, kandungan gizi, pola menu dan frekuensi makan sehari serta jenis menu.

4. Tidak adanya prosedur Pengolahan Bahan Makanan

Prosedur pengelolaan bahan makanan merupakan rincian akan kegiatan pengelolaan makanan yang dibuat dengan mengacu kepada Buku Panduan Pelayanan Gizi di Rumah Sakit. Standar prosedur yang telah ada tidak mengacu kepada buku panduan pelayanan, standar prosedur yang telah ada dibuat hanya berdasarkan kebiasan yang telah ada. Sehingganya, standar pemberian makanan pasien tidak sesuai dengan ketentuan di PGRS.

5. Tidak adanya pelatihan dan pendidikan tentang manajemen pengelolaan makanan Petugas di Instalasi gizi di RSUD X berjumlah 12 orang yang terdiri 3 Registered Dietisien dan 9 Teknikal Registered Dietisien (TRD) berdasarkan standar rumah sakit tipe C harusnya memiliki 18 Registered Dietisien dan 12 Teknikal Registered Dietisien (TRD). Tidak adanya penghitungan kebutuhan tenaga ahli berdasarkan beban kerja, serta tidak adanya program diklat baik internal maupun eksternal yang diprogramkan oleh rumah sakit. Pembinaan tenaga bertujuan untuk untuk memberi, memperoleh, meningkatkan serta mengembangkan kompetensi kerja, produktivitas, disiplin, sikap dan etos kerja pada tingkat keterampilan dan keahlian tetertentu, sesuai dengan jenjang dan kualifikasi jabatan atau pekerjaan.

6. Minimnya sarana dan prasarana

Sarana dan prasarana merupakan fasilitas penunjang yang diperlukan untuk kelancaran kegiatan pengolahan makanan di instalasi gizi. Kelengkapan sarana dan prasarana akan memberikan kemudahan dalam memberikan pelayanan gizi yang terbaik. Berdasarkan PGRS disebutkan ketersedian ruangan konseling gizi, kelengkapan komputer dan kelengkapan peralatan kerja serta peralatan antropometri yang terkalibrasi adalah sayarat wajib dalam melakukan asesmen gizi untuk pasien. Perlunya monitoring dan inventarisir peralatan serta penganggaran untuk maintenance peralatan agar memberikan pengukuran yang valid dalam setiap proses pelayanan.

7. Alur pengelolaan makanan yang tidak searah

Berdasarkan pengamatan alur pengolahan makanan bolak balik dari ruangan penyimpanan sampai dengan penyajian makanan. Pemremroses pengolahan makanan mulai dari penerimaan sampai dengan distribusi hanya melalui satu pintu. Serta ruangan instalasi gizi yang bersebelahan dengan ruang laundry. Dalam salah satu syarat dalam pembangunan sarana fisik Instalasi gizi harus tidak boleh berdekatan dengan tempat pembuangan sampah, kamar jenazah, ruang cuci (laundry). Alur yang tidak searah ini menyebabkan kelelahan dalam bekerja dikarenakan pekerjaan tidak efektif.

8. Tidak adanya pemeriksaan sampel makanan

Pemeriksaan sampel makanan merupakan salah satu cara untuk meguji kualitas pelayanan gizi. Pemeriksaan sampel makanan dimaksudkan untuk mengetahui kualitas pengendalian dari 4 faktor penyehatan makanan yaitu tempat atau bangunan, peralatan yang digunakan, orang yang mengolah dan bahan yang diolah agar mencegah food borne disease dan keracunan makanan. Oleh karenanya perlu dipastikan makanan dan minuman yang akan disajikan memiliki angka $0 / 100 \mathrm{ml}$ angka kuman e.coli untuk setiap sampel ${ }^{7}$. Akan tetapi sampai saat ini belum ada pemeriksaan sampel makanan yang dilakukan.

9. Kurangnya sarana prasarana untuk hygiene sanitasi

Sarana dan prasarana untuk menjaga hygiene dan sanitasi makanan antara lain adanya alat pengukur suhu dan kelembaban ruangan, pembersihan peralatan makan menggunakan detergen/sabun dan air panas.

10. Tidak adanya pelatihan kesehatan keselamatan dan penggunaan APAR. Masih adanya petugas yang tidak menggunakan APD

Minimnya pelatihan termasuk tatacara penggunaan APAR merupakan salah satu diklat wajib kepada petugas, tidak adanya APAR yang termaintenance dengan baik. Rentannya 
area pengolahan makanan dengan bahaya kebakaran maka kedua faktor ini merupakan hal yang wajib dipenuhi di instalasi ini. Alat Pelindung Diri (APD) merupakan salah satu faktor yang mampu mengurangi resiko pencemaran makanan dari pengolah makanan serta resiko terpaparnya petugas dengan bahaya yang ada dilingkungan kerjanya.

11. Tidak dilakukannya penelitian dan pengembangan

Penelitian dan pengembangan merupakan upaya pengembangan dan perbaikan dari instalasi gizi di sebuah rumah sakit.

\section{Identifikasi Penyebab Masalah}

Berdasarkan hasil observasi dan wawancara yang dibandingkan dengan Pedoman PGRS, maka dilakukan wawancara analisis penyebab akar masalah dengan menggunakan metode fishbone. Metode ini digunakan untuk menentukan akar penyebab utama masalah yang dibagi ke dalam 4 klasifikasi penyebab :

Tabel 2. Identifikasi Penyebab Masalah

\begin{tabular}{ll}
$\begin{array}{c}\text { Faktor } \\
\text { Penyebab }\end{array}$ & \multicolumn{1}{c}{ Penyebab Masalah } \\
\hline 1. Lingkungan & $\begin{array}{l}\text { Tidak adanya pengawasan Instlasi gizi dari kesehatan lingkungan tentang } \\
\text { Sanitasi }\end{array}$ \\
\hline \multirow{2}{*}{ 2. Manusia } & $\begin{array}{l}\text { Belum adanya perencanaan Pelatihan dan Bimbingan Teknis Mengenai } \\
\text { Manajemen Pelayanan Gizi Rumah Sakit }\end{array}$ \\
\cline { 2 - 2 } & Belum berjalannya monitoring dan evaluasi \\
\cline { 2 - 2 } & Adanya Petugas yang Tidak Patuh Menggunakan APD \\
\cline { 2 - 2 } 3. Material & Minimnya Peralatan Pengolahan Makanan \\
\hline \multirow{2}{*}{ 4. Metode } & Belum Tertatanya Alur di Ruangan Instalasi Gizi \\
\cline { 2 - 2 } & Belum Ada Buku Panduan Pengelolaan Pelayanan Gizi \\
\cline { 2 - 2 } & Pendokumentasian POP Pelayananan Ban Belum Baik \\
\hline
\end{tabular}

Berdasarkan tabel identifikasi penyebab masalah diatas dapat digambarkan akar penyebab masalah pengelolaan makanan di instalasi gizi RSUD $\mathrm{X}$ adalah sebagai berikut:

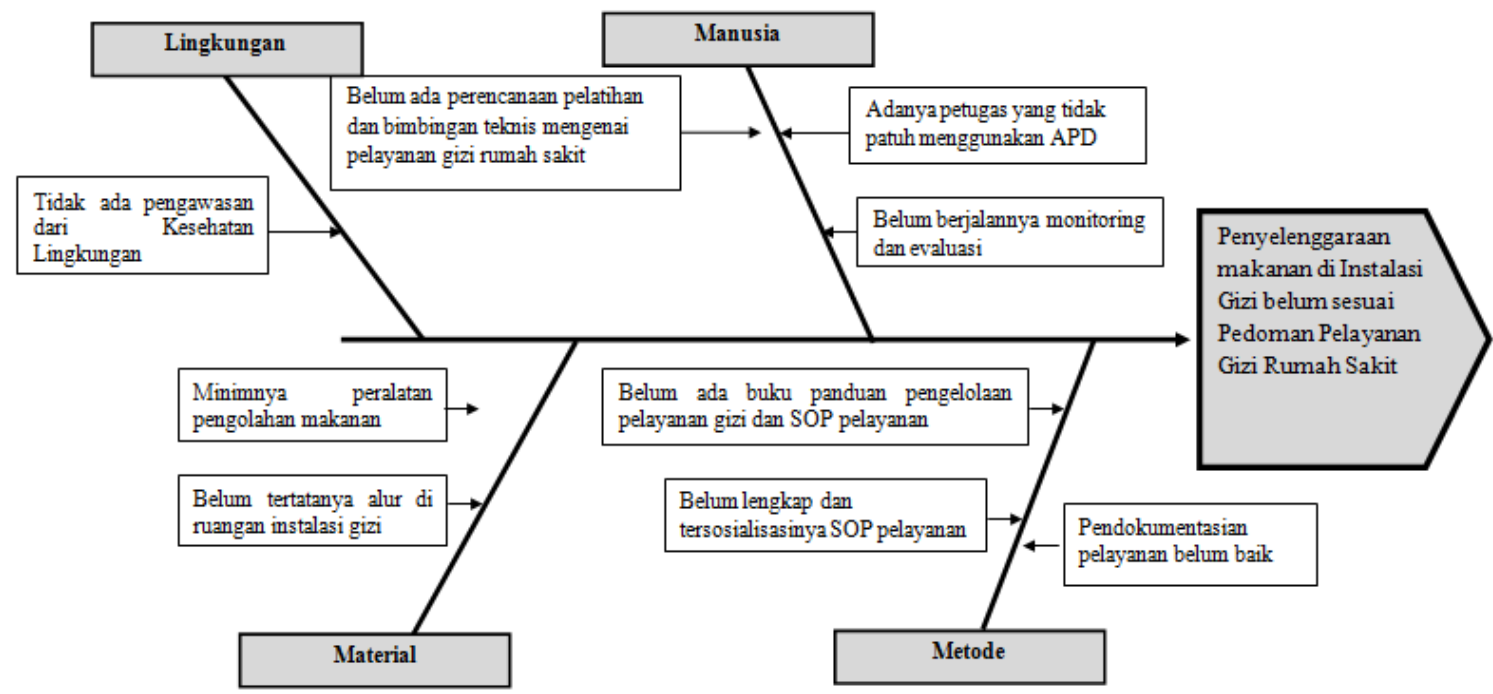

Gambar 1. Diagram Fishbone Pengelolaan Instalasi Gizi RSUD Arosuka 


\section{Alternatif Pemecahan Masalah}

Berdasarkan analisa penyebab masalah diatas maka dirumuskan alternatif pemecahan masalah berdasarkan buku pedoman dan peraturan menteri kesehatan yang dapat dilakukan untuk upaya peningkatan pelayanan pengolahan makanan di Instalasi Gizi RSUD X.

Tabel 3. Alternatif Pemecahan Masalah

\begin{tabular}{|c|c|}
\hline Penyebab Masalah & Alternatif Pemecahan Masalah \\
\hline \multicolumn{2}{|l|}{ Faktor Lingkungan } \\
\hline $\begin{array}{lr}\text { Tidak ada } & \text { pengawasan } \\
\text { dari } & \text { Kesehatan } \\
\text { Lingkungan } & \end{array}$ & $\begin{array}{l}\text { 1. Bagian kesehatan lingkungan melakukan pengawasan akan angka } \\
\text { bebas kuman dan bebas binatang pengganggu di Instalasi Gizi }\end{array}$ \\
\hline \multicolumn{2}{|l|}{ Faktor Manusia } \\
\hline $\begin{array}{l}\text { Pelatihan dan Bimbingan } \\
\text { Teknis mengenai } \\
\text { pelayanan gizi rumah sakit } \\
\text { belum ada }\end{array}$ & $\begin{array}{l}\text { 1. Menjalin kerjasama dengan Rumah Sakit yang sudah terakreditasi } \\
\text { paripurna (RSI Ibnu Sina Bukittinggi). Lakukan pelatihan dan } \\
\text { bimbingan tekhnis inhouse training dengan melibatkan petugas } \\
\text { pengolahan dan kasie penunjang medis. } \\
\text { 2. Melakukan inhouse training } \\
\text { 3. Mengikuti training manajemen pengelolaan makanan yang } \\
\text { diadakan oleh institusi swasta }\end{array}$ \\
\hline $\begin{array}{l}\text { Ketidakpatuhan petugas } \\
\text { dalam penggunaan APD }\end{array}$ & $\begin{array}{l}\text { 1. Dilakukannya monitoring dan evaluasi kerja } \\
\text { 2. Pemberian reward dan punishment }\end{array}$ \\
\hline \multicolumn{2}{|l|}{ Faktor Material } \\
\hline $\begin{array}{l}\text { Minimnya Peralatan } \\
\text { Pengolahan Makanan }\end{array}$ & $\begin{array}{l}\text { 1. Pengkajian peralatan pengolahan makanan yang dibutuhkan dan } \\
\text { disesuaikan dengan standar PGRS } \\
\text { 2. Pengajuan anggaran untuk peralatan pengolahan makanan }\end{array}$ \\
\hline $\begin{array}{l}\text { Belum Tertatanya Alur di } \\
\text { Ruangan Instalasi Gizi }\end{array}$ & $\begin{array}{l}\text { 1. Pengkajian untuk perombakan alur pengelolaan makanan } \\
\text { 2. Perencanaan perubahan ruangan instalasi gizi yang disesuaikan } \\
\text { dengan alur yang baik } \\
\text { 3. Pengajuan anggaran untuk perubahan ruangan instalasi gizi }\end{array}$ \\
\hline \multicolumn{2}{|r|}{ 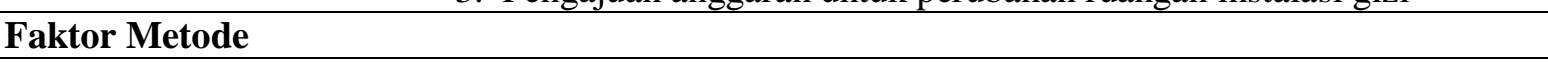 } \\
\hline $\begin{array}{l}\text { Belum Ada Buku Panduan } \\
\text { Pengelolaan } \quad \text { Pelayanan } \\
\text { Gizi }\end{array}$ & $\begin{array}{l}\text { 1. Pembuatan Buku pedoman pelayanan gizi berdasarkan standar- } \\
\text { standar pengelolaan gizi, pangan dan rumah sakit yang berlaku di } \\
\text { Indonesia, seperti Pedoman Pelayanan Gizi Rumah Sakit (PGRS), } \\
\text { KMK No } 129 \text { Tentang Standar Pelayanan Minimum, UU Nomor 56 } \\
\text { Tentang Klasifikasi Rumah Sakit, PMK Nomor } 26 \text { tentang Praktik } \\
\text { Gizi dan sebagainya. }\end{array}$ \\
\hline $\begin{array}{l}\text { Belum lengkapnya SOP } \\
\text { Pelayanan }\end{array}$ & $\begin{array}{l}\text { 1. Pengkajian dan pembuatan SOP yang diperlukan dalam pelayanan } \\
\text { gizi dengan membandingkan Peraturan-peraturan yang telah } \\
\text { ditetapkan Pemerintah serta melakukan studi banding dengan } \\
\text { rumah sakit yang telah terakreditasi paripurna seperti RSI Ibnu Sina } \\
\text { Bukittinggi } \\
\text { 2. Pembuatan SOP pelayanan gizi }\end{array}$ \\
\hline $\begin{array}{l}\text { Pendokumentasian } \\
\text { Pelayanan Belum Baik }\end{array}$ & $\begin{array}{l}\text { 1. Pembuatan formulir pelayanan gizi yang lengkap, mulai dari } \\
\text { formulir konseling, formulir pemintaan diet dan sebagainya. } \\
\text { 2. Merekap lembaran konseling setiap bulannya dengan komputerisasi } \\
\text { 3. Pengevaluasian lembaran dokumen } \\
\text { 4. Pengkoordinasian pelayanan dengan petugas kesehatan lainnya } \\
\text { dengan baik agar dokumen terlengkapi }\end{array}$ \\
\hline
\end{tabular}

Berdasarkan alternatif tersebut pimpinan dan manajemen rumah sakit dapat membuat proritas dalam menyelesaikan penyebab permasalahan di Instalagi Gizi RSUD X. 


\section{Kesimpulan}

Berdasarkan hasil pengamatan, akar permasalahan di pelayanan penyelenggaraan makanan di Instalasi Gizi RSUD X Kota Solok dapat dikelompokkan berdasarkan 4 faktor penyebab masalah. Faktor lingkungan berupa tidak ada adanya pengawasan dari unit kesehatan lingkungan, berdasarkan dari faktor manusia akar penyebabnya kurangnya pelatihan dan bimbingan teknis mengenai pelayanan gizi rumah sakit serta kesadaran dan kepatuhan dalam penggunaan alat pelindung diri. Untuk faktor material, masalah teridentifikasi adalah minimnya peralatan pengolahan makanandan belum tertatanya alur di Instalasi Gizi dengan baik. Sedangkan untuk faktor metode diketahui akar penyebab masalahnya adalah belum adanya Panduan Pelayanan Instalasi Gizi, minimnya SOP serta pendokumentasian pelayanan yang belum baik.

\section{Referensi}

[1] Muliawardani, R. Mudayana, A.A.; Analisis Manajemen Pelayanan Gizi di Rumah SakitJiwa (RSJ) Grhasia Daerah Istimewa Yogjakarta. KESMAS, Vol.10, No.1. (25-34). Universitas Ahmad Dahlan. Yogjakarta : 2016

[2] Herawati, D.M.D. Rafisa, A. Yani, A. Analisis Pelayanan Gizi Rumah Sakit dengan Pendekatan. Health Technology Assessement (HTA). JSK. Vol.1 (2). Bandung: 2015

[3] Pedoman Pelayanan Rumah Sakit Kementerian Kesehatan RI Tahun 2013

[4] Zuriah, Nurul, 2009. Metodelogi Penelitian Sosial dan Pendidikan. Jakarta : Bumi Aksara

[5] Supomo. Nur Indriantoro, 2004, Metodologi Penelitian Bisnis, Cetakan Kedua, Yogyakara; Penerbit BFEE UGM

[6] Sarwono, Jonathan, 2006. Metode Penelitian Kuantitatif dan Kualitatif. Yogyakarta : Graha Ilmu

[7] Keputusan Kementrian Kesehatan Republik Indonesia Nomor 129 tahun 2008 Tentang Standar Pelayanan Minimal Rumah Sakit

[8] Peraturan Menteri Kesehatan Republik Indonesia Nomor 78 Tahun 2013 Tentang Pedoman Pelayanan Gizi Rumah Sakit. 